\title{
Field dependence and interpersonal distance
}

\author{
LINDA M. KLINE, PAUL A. BELL, and A. MICHAEL BABCOCK \\ Colorado State University, Fort Collins, Colorado
}

\begin{abstract}
Undergraduates were tested for field dependence on the rod-and-frame apparatus (Experiment 1) or the embedded-figures test (Experiment 2). Thirty-one field-dependent (12 male, 19 female) subjects and 35 field-independent (21 male, 14 female) subjects had the distance between themselves and a male or female confederate of the experimenter measured on an interpersonal distance mat. Although results of both experiments did not yield significant results, when data were combined, results supported the hypothesis that field-dependent persons stood closer to the confederate than did field-independent persons. Results were explained in terms of different cognitive styles relying on different information in the environment.
\end{abstract}

A number of individual difference measures have been shown to influence interpersonal distancing. For example, extroverts maintain closer interpersonal distances than introverts (Cook, 1970; Patterson \& Holmes, 1966), and individuals low in anxiety maintain closer distances than those high in anxiety (Karabenick \& Meisels, 1972). Such studies might imply that individuals confident and eager to interact with the social and physical environment are "attuned" to that environment and thus are willing to interact with others at relatively close distances. On the other hand, those less confident, or those who perhaps are more secure with less interaction with their social and physical surroundings, maintain greater distances between themselves and others.

A concept that may relate to this idea is that of cognitive style. Research on cognitive style has shown that field-dependent persons tend to rely on the environment as a primary referent in perceptual judgments, whereas field-independent persons rely on some internal referent in making judgments (Witkin, Dyk, Faterson, Goodenough, \& Karp, 1974). Other research shows that these cognitive styles influence interpersonal behaviors. For example, Busch and DeRidder (1973) found that field-dependent subjects were more influenced by opinions of others with whom they interacted than were field-independent subjects. Moreover, descriptions of field-dependent subjects given by themselves and others contain such terms as friendly, considerate, warm, and affectionate. In contrast, field-independent subjects are described by themselves and others as ambitious, interested in power, and manipulative of other people (Elliot, 1961; Loveless, 1972).

Consistent with this research, it might be expected that cognitive style would influence interpersonal dis-

Portions of these data were presented at the 1981 meeting of the Rocky Mountain Psychological Association. The authors express appreciation to Henry A. Cross for his helpful advice on this research and to Marshall Breeding, Terry Guyton, Paul Hobson-Panico, and Richard Kirnan for their assistance in the collection of the data. Requests for reprints should be sent to Paul A. Bell, Department of Psychology, Colorado State University, Fort Collins, CO 80523. tancing. Field-dependent persons, who rely on the environment and are perhaps more sociable, would be expected to interact at closer distances than fieldindependent persons, who rely less on the environment. The present study reports two experiments that sought to test this hypothesis.

\section{EXPERIMENT 1}

\section{Method}

The subjects were 35 male and 47 female general psychology students whose participation satisfied part of a course requirement. Each subject was tested for field dependence using the rod-and-frame apparatus. The subject was then led to another room, and the distance between the subject and a confederate of the experimenter was measured on an interpersonal distance mat (Barnard \& Bell, 1982). A confederate (male or female) stood at one end of the mat and the subject walked toward the person, stopping when the subject felt that any closer would be uncomfortable. The mat was wired such that distance in inches could be read in another room.

\section{Results}

Of the 82 subjects, only 25 could be classified as field dependent ( 4 males, 8 females) or field independent (10 males, 3 females). A sex of subject $x$ field dependence factorial analysis of variance revealed no significant effects, including the main effect for field dependence $[F(1,21)=2.91, p<.10]$. Field-dependent persons maintained an average distance of 10.00 in. $(25.40 \mathrm{~cm})[\mathrm{SD}=3.70$ in. $(9.32 \mathrm{~cm})]$ from the confederate, whereas field-independent persons maintained an average distance of 15.23 in. $(38.69 \mathrm{~cm})$ [SD $=1.82 \mathrm{in}$. $4.59 \mathrm{~cm})$ ] . Experiment 2 was conducted to examine the reliability of these means.

\section{EXPERIMENT 2}

\section{Method}

The subjects were 41 general psychology students who completed a course requirement by participating in the study. The cognitive style of each subject had been classified previously using the embedded-figures test; 22 subjects $(11$ males, 11 females) were classified as field independent, and 19 subjects 
(9 males, 10 females) were classified as field dependent. Upon arriving at the experimental room, each subject approached a confederate of the experimenter, and the distance between them was measured on the interpersonal distance mat.

\section{Results}

A $2 \times 2 \times 2$ analysis of variance was conducted, with factors of sex of subject, sex of confederate, and field dependence. Again, none of the effects was significant, including the main effect for field dependence $[\mathrm{F}(1,33)$ $=2.67, \mathrm{p}<.15]$. Field-dependent persons maintained an average of 12.47 in. $(31.67 \mathrm{~cm})$ [SD $=2.05 \mathrm{in}$. $(5.17 \mathrm{~cm})]$ from the confederate, and field-independent persons averaged $14.64 \mathrm{in} .(37.19 \mathrm{~cm})$ [SD $=4.48 \mathrm{in}$. $(11.29 \mathrm{~cm})]$.

Because the results of both experiments had similar trends, they were combined in a $2 \times 2 \times 2 \times 2$ analysis of variance, with factors of sex of subject, sex of confederate, field dependence, and experiment (1 or 2). The results indicated that field-dependent persons stood significantly closer $[\mathrm{F}(1,50)=6.19, \mathrm{p}<.05]$ to the confederate $[$ mean $=11.52$ in.$(29.26 \mathrm{~cm}) ; \mathrm{SD}=$ 3.03 in. $(7.64 \mathrm{~cm})]$ than did field-independent persons [mean $=14.86$ in. $(37.74 \mathrm{~cm}) ; \mathrm{SD}=3.77$ in. $(9.50 \mathrm{~cm})]$. The sex of subject $x$ sex of confederate $x$ experiment interaction was also significant $[\mathrm{F}(1,50)=4.48, \mathrm{p}<.05]$. The results of a Newman-Keuls test indicated no significant differences between the means. No other main effects or interactions were significant.

\section{DISCUSSION}

The results lend support to the proposal that field-dependent persons maintain closer distances to other persons than do field-independent persons, although the magnitude of the effect appears to be small $\left(\eta^{2}=.088\right)$. This finding is consistent with research by Justice (1970), who found that field-dependent subjects stood significantly closer to the experimenter while presenting a topic orally than did field-independent subjects. Justice theorized that oral presentation of a prepared topic was a stressful situation and that field-independent persons saw themselves as a means of reducing the resulting anxiety, whereas field-dependent subjects saw the experimenter as the source of anxiety reduction, which resulted in a difference in distancing preference. The present study found the same relationship in distancing in a very different situation. If anything, approaching a complete stranger should be anxiety provoking, and therefore closer distances could not be interpreted as anxiety reducing for either cognitive style. Thus, reducing stress or anxiety may not explain distance preferences of field-dependent or field-independent persons. Rather, these distance differences may be simply a matter of differences in reliance upon information in the environment. That is, field-dependent individuals may be more reliant upon information in the environment, and therefore may approach others more closely than fieldindependent individuals in order to use that information more thoroughly.

\section{REFERENCES}

Barnard, W. A., \& Bell, P. A. (1982). An unobtrusive apparatus for measuring interpersonal distances. Journal of General Psychology, 107, 85-90.

Busch, J. C., \& DeRidder, L. M. (1973). Conformity in preschool disadvantaged children as related to field dependence, sex, and verbal reinforcement. Psychological Reports, 32, 667-673.

Cook, M. (1970). Experiments on orientation and proxemics. Human Relations, 23, 61-76.

Elliot, R. (1961). Interrelationships among measures of field dependence, ability, and personality traits. Journal of $A b$ normal and Social Psychology, 63, 27-36.

Justice, M. T. (1970). Field dependency, intimacy of topic, and interperson distance. Dissertation Abstracts International, 31, 395B-396B.

Karabenick, S. A., \& Meisels, M. (1972). Effects of performance evaluation on interpersonal distance. Journal of Personality, 40, 275-286.

Loveless, E. J. (1972). Cognitive styles, orienting responses, and self-report measures of personality. Journal of Personality Assessment, 36, 273-281.

Patterson, M. L., \& Holmes, D. S. (1966). Social interaction correlates of MMPI extraversion-introversion scale. American Psychologist, 21, 724-725.

Witkin, H. A., Dyk, R. B., Faterson, H. F., Goodenough, D. R., \& KARP, S. A. (1974). Psychological differentiation. Potomac, MD: Erlbaum.

(Manuscript received for publication March 19, 1984.) 